Toshiaki Nakajima • Ituro Inoue · Tong Cheng Jean-Marc Lalouel

\title{
Molecular cloning and functional analysis of a factor that binds to the proximal promoter of human angiotensinogen
}

Received: October 9, 2001 / Accepted: October 22, 2001

\begin{abstract}
A significant association has been reported between a common variant in the angiotensinogen gene $(A G T)$, allele T235, and essential hypertension. In subsequent work, it was found that another variant, the presence of an adenine instead of a guanine $6 \mathrm{bp}$ upstream from the initiation site of transcription, was in absolute linkage disequilibrium with T235. The nucleotide substitution at the -6 position affected the formation of DNA-protein complexes in gel mobility shift assays and the basal transcription of $A G T$ in transactivation experiments. We have further examined the potential impact of this polymorphism on $A G T$ promoter function. In ultraviolet cross-linking analysis, 150 - and $75-\mathrm{kD}$ a proteins bound to the $A G T$ proximal promoter. The possible involvement of factors that bind to GC-rich domains, including Sp1, Sp3, and AP2, was not supported by gel mobility shift assays. Screening an expression library with a double-stranded DNA segment centered on -6 led to the isolation of cDNA clones encoding the YB1 protein. The specificity of the interaction of YB1 with the proximal promoter of $A G T$ was verified by Southwestern blotting and gel mobility shift assays. In cotransfection experiments, YB1 reduced basal $A G T$ promoter activity in a dose-dependent manner. Although these observations suggest a possible role for YB1 in modulating $A G T$ expression, this function is likely to occur in the context of complex interactions involving other nuclear factors. The work illustrates the challenge of developing a molecular understanding of the relationship between common genetic variants and conditions that are only partly caused by them.
\end{abstract}

Key words Angiotensinogen - Transcriptional control · Cloning · Transcription factor · YB1 · Essential hypertension

T. Nakajima $\cdot$ I. Inoue $\cdot$ T. Cheng $\cdot$ J.-M. Lalouel $(\square)$

Department of Human Genetics, University of Utah, 15 North 2030

East, Room 6200, Salt Lake City, UT 84112-5331, USA

Tel. +1-801-581-3027; Fax +1-801-587-9045

e-mail: jml@howard.genetics.utah.edu

T. Nakajima $\cdot$ I. Inoue

Division of Genetic Diagnosis, Institute of Medical Science,

University of Tokyo, Tokyo, Japan

\section{Introduction}

Although only partial causation can be expected of any genetic determinant of essential hypertension, the search is motivated by the hope that it will provide new leads to the pathophysiology of the condition. Genetic studies can incriminate genomic regions or even specific genes. The functional analysis of such genetic hints remains daunting, however.

Genetic linkage and association with the T235 allele of the angiotensinogen gene $(A G T)$ support the hypothesis that molecular variation in the gene modulates individual predisposition to essential hypertension (Jeunemaitre et al. 1992; Kato et al. 1999; Kunz et al. 1997). Such genetic inference, however, provides no functional clue. In subsequent analyses, a common variant in the proximal promoter of $A G T$, the substitution of adenine for guanine six nucleotides upstream from the initiation site of transcription, was found in quasi-absolute linkage disequilibrium with the T235 variant (Inoue et al. 1997). Although no functional difference could be identified between recombinant proteins carrying the T235 or the M235 allele, the A/G (-6) polymorphism led to significant differences in both specific interactions with nuclear proteins and promoter activity in vitro (Inoue et al. 1997).

The goal of the present study was to identify nuclear factors that can act in trans at the site of the $\mathrm{A} / \mathrm{G}(-6)$ polymorphism and modulate the basal expression of $A G T$. Through screening of expression libraries, we identified a cDNA encoding YB1 protein. Further experiments suggest that the protein can bind to the proximal promoter of $A G T$ and can modulate its function in vitro.

\section{Methods}

Plasmid construction for promoter studies

From one to four copies of a 23-mer oligonucleotide, centered on nucleotide -6 of $A G T$, and with either $\mathrm{G}(\mathrm{G} 23)$ 
or A (A23) at this site, were inserted upstream from the SV40 promoter/Luciferase reporter fusion gene, using the pGL2 vector (Promega, Madison, WI, USA). Similarly, from one to three copies of either G23 or A23 were placed upstream from the adenovirus major late promoter at the SalI cloning site of the pMT2 expression vector (Genetics Institute, Cambridge, MA, USA). An $A G T$ promoter segment spanning nucleotides -256 to +90 , with $\mathrm{G}$ at the -6 position, was enzymatically amplified, and additional restriction enzyme sites were created during the amplification. After digestion with KpnI and HindIII, the AGT promoter segments were placed upstream from the Luciferase reporter in the promoterless pGL3-basic vector (Promega). All inserts were verified in their entirety by DNA sequencing.

Transfection and reporter assay

HepG2 cells were cotransfected with $1 \mu \mathrm{g}$ test vector and $0.1 \mu \mathrm{g}$ control vector encoding Renilla Luciferase (pRLSV40, Promega) following a calcium phosphate protocol using modified bovine serum (MBS) (Stratagene, La Jolla, CA, USA). Briefly, the cells were plated onto 12-well plastic dishes at $1 \times 10^{5}$ per dish, and cultured for $24 \mathrm{~h}$ before transfection. At the time of transfection, the medium was changed to 6\% MBS in Dulbecco's Modified Eagle's Medium (DME). Each experiment involved triplicate or quadruplicate dishes for each construct as well as positive and negative controls. Twenty-four hours following transfection, the cells were harvested with a lysis buffer (Promega), and reporter activity was measured using a Dual-Luciferase Reporter Assay System in a luminometer (Promega).

\section{Gel mobility shift assay}

Nuclear extract from HepG2 cells was prepared as described (Dignam 1983). Synthetic single- or doublestranded oligonucleotides labeled with $\left[\gamma_{-}{ }^{32} \mathrm{P}\right]$ ATP by a kination reaction and then purified on $8 \%$ native polyacrylamide gels were used as probes in gel mobility shift assay as described (Giarabedian et al. 1993). The binding reaction $(20 \mu \mathrm{l})$ contained $10 \mathrm{mM}$ hydroxyethylpiperazine ethanesulfonic acid (HEPES) ( $\mathrm{pH} 7.9$ ), $5 \mathrm{mM} \mathrm{MgCl}_{2}, 1 \mathrm{mM}$ ethylenediaminetetraacetate (EDTA), $0.5 \mathrm{mM}$ dithiothreitol (DTT), $100 \mathrm{mM} \mathrm{KCl}, 10 \%$ glycerol, and $2 \mu \mathrm{g}$ of polydeoxyinosinic-deoxycytidylic acid. Nuclear extract $(5 \mu \mathrm{g})$ was preincubated with the binding buffer on ice for $20 \mathrm{~min}$, followed by incubation with radiolabeled probe at $25^{\circ} \mathrm{C}$ for $15 \mathrm{~min}$. The binding reaction was resolved on a $4 \%$ native polyacrylamide gel in $0.5 \mathrm{X}$ Tris-borate + EDTA buffer. After electrophoresis at $200 \mathrm{~V}$ for $2 \mathrm{~h}$, the gels were dried and exposed to Kodak XAR film at $-80^{\circ} \mathrm{C}$. Competition experiments were performed by adding a 100-fold molar excess of unlabeled single- or double-stranded oligonucleotides to the preincubation mixture. The sense single-stranded $\mathrm{G}(\mathrm{A}) 23$ oligonucleotide was 5'-GTGACC CGGCCG(A)GGGGAAGAAGC-3', and the antisense single-stranded $\mathrm{G}(\mathrm{A}) 23$ oligonucleotide was 5'-GCTTCTT
CCCCC(T)GGCCGGGTCAC-3'. When indicated, antibodies against Sp1, Sp3, AP2 (Santa Cruz Biotechnology, Santa Cruz, CA, USA), or YB1 (a gift from Dr. Jenny P.-Y. Ting, University of North Carolina, Chapel Hill, NC) were added to the preincubation mixture.

\section{UV cross-linking}

After gel mobility shift assay was performed as described earlier, the gel was removed, wrapped with Saran wrap, irradiated with UV at a wave length of $254 \mathrm{~nm}$ for $20 \mathrm{~min}$, and placed on Kodak XAR film for 4-5h at room temperature. The retarded bands were excised and boiled in a sample buffer of sodium dodecyl sulfate-polyacrylamide gel electrophoresis (SDS-PAGE) for 2-3 min. The samples were loaded and separated on $8 \%$ SDS-PAGE gels followed by autoradiography.

\section{Expression cloning}

A $\lambda$-gt11 human leukemia library from the MOLT4 cell line and a $\lambda$-gt11 human placenta cDNA expression library (Clontech, Palo Alto, CA, USA) were screened for a binding factor with the radiolabeled G23 oligonucleotide, proceeding through isopropyl thiogalactoside (IPTG) induction of fusion proteins, guanidinium denaturation/ renaturation, and hybridization with radiolabeled DNA probes as described by Singh et al. (1988). Positive clones were subcloned into pBluescript-SK $(+)$, and sequenced.

\section{Preparation of GST/YB1 fusion protein}

The GST/YB1 fusion protein was produced using the expression vector pGEX2T (Amersham-Pharmacia Biotech, Piscataway, NJ, USA) including the entire coding sequence of YB1, which was a gift from Dr. Jenny P.-Y. Ting. The bacterial transformants were grown to an optical density of 0.6 to 0.8 at $600 \mathrm{~nm}$ and thereafter induced with $1 \mathrm{mM}$ IPTG for $2 \mathrm{~h}$ at $37^{\circ} \mathrm{C}$. The fusion proteins were purified with glutathione-Sepharose beads (Amersham-Pharmacia Biotech) and eluted with $50 \mathrm{mM}$ Tris- $\mathrm{HCl}$ ( $\mathrm{pH} 7.4)$ containing $15 \mathrm{mM}$ reduced glutathione (Smith and Johnson 1988).

\section{Southwestern blots}

Purified GST/YB1 fusion protein (100ng) was separated on $10 \%$ SDS-PAGE gels and transferred to Hybond-C membrane (Amersham-Pharmacia Biotech) using a standard protocol. The membranes were subjected to guanidinium hydrochloride denaturation/renaturation as previously described (Vinson et al. 1988). The membranes were blocked with $5 \%$ dry milk, and washed with a binding buffer $(50 \mathrm{mM}$ $\mathrm{KCl}, 10 \mathrm{mM}$ HEPES at $\mathrm{pH} 7.0,1.0 \mathrm{mM}$ EDTA, $6.4 \mathrm{mM}$ $\mathrm{MgCl}_{2}, 1.0 \mathrm{mM}$ DTT). The membranes were hybridized in binding buffer containing $0.25 \%$ dry milk with the indicated radiolabeled probe $\left(1 \times 10^{6} \mathrm{cpm} / \mathrm{ml}\right)$ for $8 \mathrm{~h}$ at room temperature. Following three washes with binding buffer for $10-15 \mathrm{~min}$, autoradiography was performed at $-70^{\circ} \mathrm{C}$. 
Coexpression of YB1 with an AGT promoter-reporter construct

The entire coding sequence of human YB1 was placed under the control of the major late promoter of adenovirus in the expression vector pMT2 to generate the pMT2/YB1 construct. The promoter segment encompassing nucleotides -256 to +90 of the human $A G T$ gene was inserted upstream from the Firefly Luciferase reporter gene in the pGL3 vector (Promega) to generate the pAGT/Luc vector. HepG2 cells were cotransfected with pAGT/Luc ( $1 \mu \mathrm{g} /$ well $)$ and pMT2/YB1 $(0,0.5,1$, and $2 \mu \mathrm{g} /$ well $)$ using an MBS mammalian transfection kit (Stratagene). The total amount of transfected DNA was kept constant by the addition of pMT2 plasmid. In all transfections, the plasmid pRL-SV40 (Promega), encoding Renilla Luciferase, was included as an internal control. Luciferase activity was measured using a Dual-Luciferase Reporter Assay System (Promega).

\section{Results}

Effects of G23 and A23 tandem repeats on transactivation of core promoters

To test for a transcriptional effect of the DNA segment encompassing nucleotide -6 of $A G T$, we performed two series of transactivation experiments. First, HepG2 cells were transfected with reporter plasmids with one to four tandem repeats of either the G23 or the A23 oligonucleotide inserted upstream from an SV40 promoter-Luciferase fusion gene in the pGL2 vector (Promega). A direct, positive relationship was observed between reporter activity and number of copies of either G23 or A23 segments (Fig. 1a), with no apparent difference between the two sequences. In a second series of experiments, competition for binding of nuclear factors was tested by cotransfecting a plasmid carrying a fusion gene consisting of the $A G T$ promoter segment spanning nucleotides -256 to +90 and the Firefly Luciferase coding sequence, together with plasmids containing from one to three repeats of either G23 or A23 placed in front of an adenovirus major late promoter with no coding insert. Although reporter expression increased when G23 was used as a competitor, no difference was observed with A23 (Fig. 1b).

\section{Characterization of a factor that binds to the proximal} promoter of AGT

Factors acting in trans on the $A G T$ promoter segment spanning the -6 region were examined by ultraviolet (UV) cross-linking of the two protein complexes revealed by gel retardation assays (Inoue et al. 1997). Cross-linking of the upper band ( $\mathrm{U}$ in Fig. 2) resulted in two proteins with estimated molecular weights of 150 and $75 \mathrm{kDa}$, respectively (Fig. 2). The lower band ( $\mathrm{L}$ in Fig. 2) yielded molecules of 80 and $50 \mathrm{kDa}$, respectively. This complex has previously been recognized as nonspecific and identified as the $\mathrm{Ku}$ autoantigen, the $80-\mathrm{kDa}$ component corresponding to the p70 DNA-binding subunit (Inoue et al. 1997).

The high GC content of the -6 region suggested a possible involvement of known GC-binding factors such as Sp1,
Fig. 1a,b. a Dose-dependent effects of G23 (closed squares) and A23 (open squares) in cisactivation of a core SV40 promoter in $\mathrm{HpG} 2$ cells. b Dose-dependent effects of G23 (closed squares) or A23 (open squares) in trans on AGT promoter (AGT-P) activity in HepG2 cells. Results are expressed in terms of mean relative activities and standard errors of the means
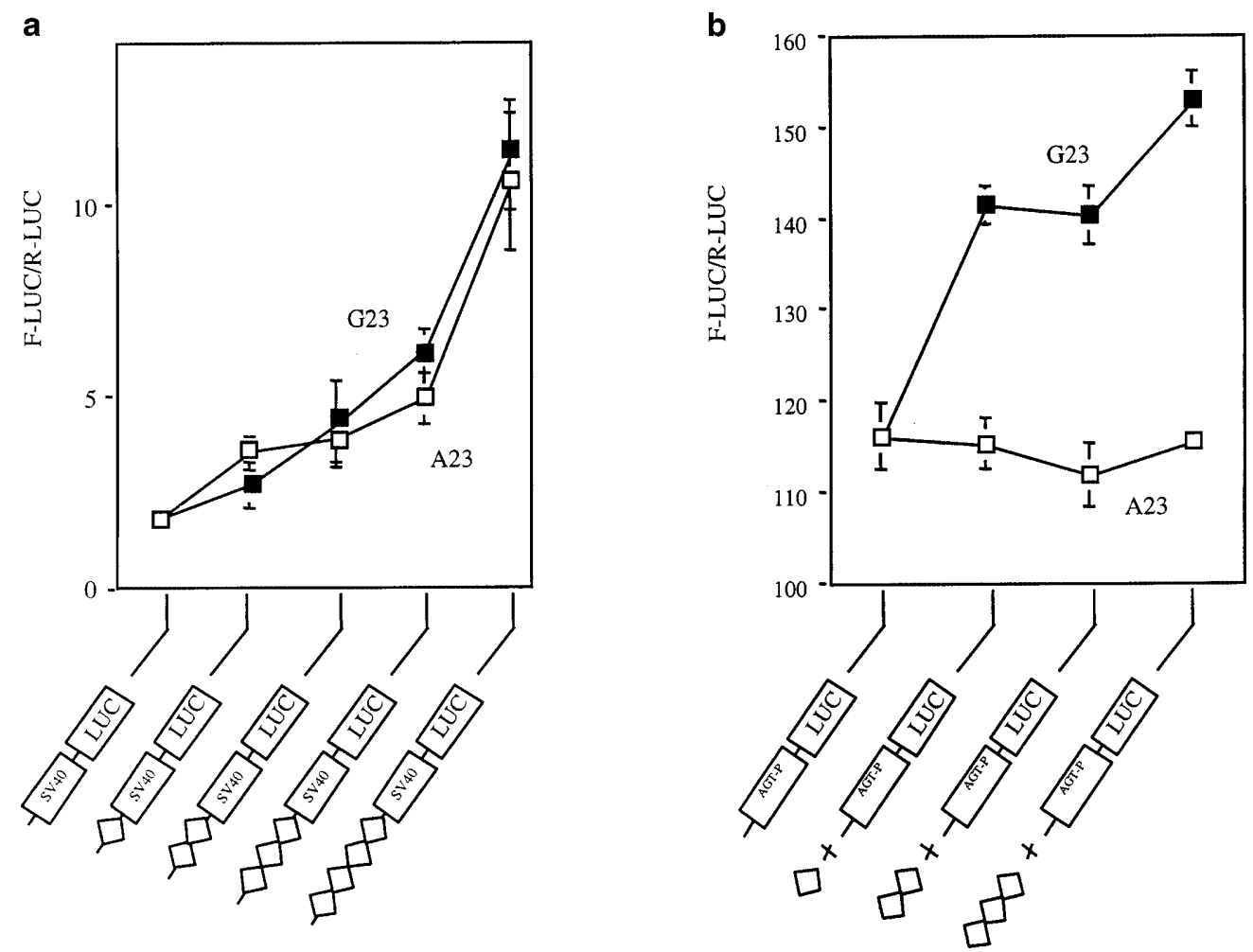
Sp3, and AP2. To address this issue, we examined whether specific antibodies could affect either binding or mobility of electrophoretically retarded complexes. As shown in Fig. 3, none of the three antibodies interfered with the retardation experiments.

\section{GMSA}

\section{UV cross-linking}

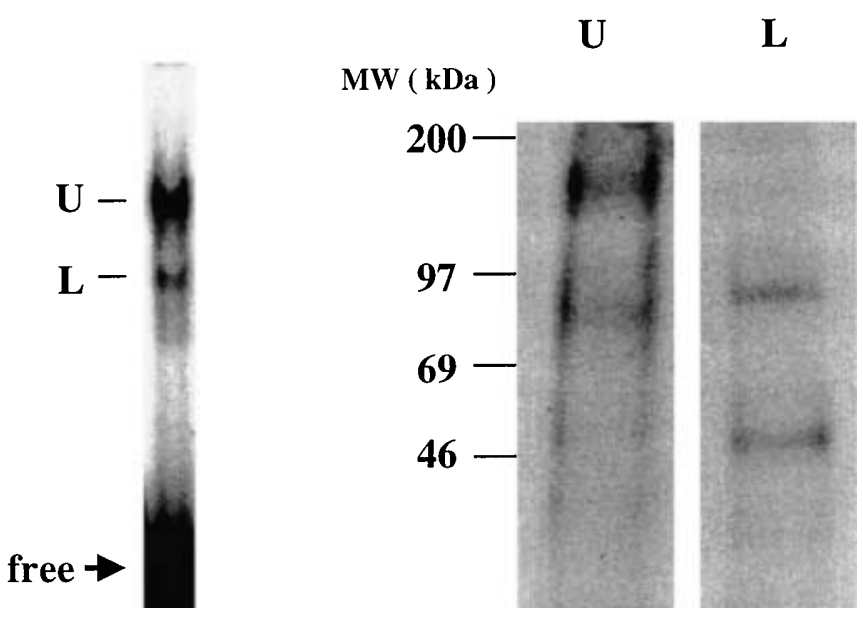

Fig. 2. Ultraviolet cross-linking of protein complexes revealed by gel retardation assays with $\left[{ }^{32} \mathrm{P}\right]$-labeled G23 oligonucleotide. Crosslinking of the upper band $(U)$ resulted in two proteins with approximate molecular weights of 150 and $75 \mathrm{kDa}$, respectively. The lower band $(L)$ yielded molecules of 80 and $50 \mathrm{kDa}$, respectively. GMSA, Gel mobility shifts assay
Isolation of cDNA encoding a protein that binds to the AGT proximal promoter

To isolate cDNA clones encoding factors binding to the proximal promoter of $A G T$, we screened $\lambda$-gt11 human leukemia and placenta libraries with radiolabeled doublestranded G23 oligonucleotide. An oligonucleotide containing the Oct-1 binding consensus sequence was used to eliminate nonspecific signals in a secondary screen. Two clones, one from each library screened, met the criteria for specific binding on such secondary screening. Complementary DNA fragments were subcloned into pBluescriptSK(+) and sequenced. Sequence analysis revealed that these two clones had overlapping sequences, and the protein encoded by the open reading frame was identified as human YB1.

\section{YB1 binds to the AGT proximal promoter}

Recombinant protein was expressed in Escherichia coli as a fusion protein with glutathione-S-transferase (GST/YB1) to evaluate the binding activity of YB1. YB1 has been previously reported to bind both double- and single-stranded DNA in a sequence-specific manner (Bayarsaihan et al. 1996; Hasegawa et al. 1991; Kolluri et al. 1992; MacDonald et al. 1995; Mertens et al. 1997; Ohmori et al. 1996). We performed gel mobility shift assay and Southwestern blots using double- and single-stranded G23 oligonucleotides. All precautions were taken to prevent the generation of single-
Fig. 3. Gel mobility shift assay with anti-Sp1, Sp2, and AP2 antibodies. None of the three antibodies interfered with either binding or mobility of the complex $(a)$ retarded by interaction with $\left.{ }^{32} \mathrm{P}\right]$-labeled $\mathrm{G} 23$ (lanes 2, 3 , and 4). By contrast, a protein complex bound to Sp1-specific oligonucleotide exhibited supershifting $(b)$ in the presence of antiSp1 antibody, whereas the same complex was markedly reduced (d) on addition of Sp3 antibodies (lanes 6 and 7). A protein complex bound to AP2 oligonucleotide exhibited supershifting $(e)$ in the presence of anti-AP2 antibodies (lanes 8 and 9 )
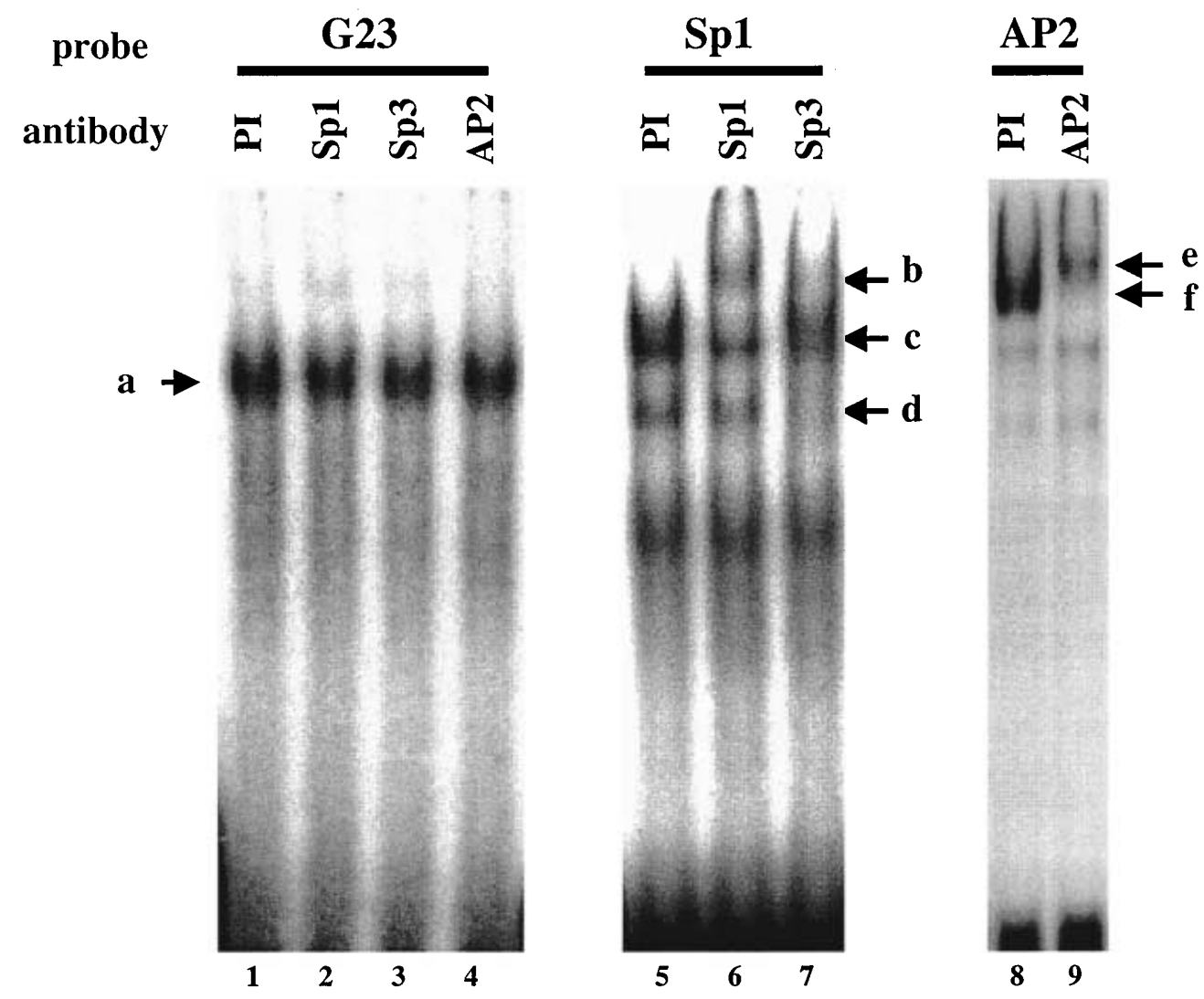
stranded DNA within the double-stranded probe. The gel mobility shift assay showed that GST/YB1 bound to antisense single-stranded G23 oligonucleotide with high affinity and bound to double-stranded G23 oligonucleotide with low affinity (Fig. 4a). No binding was observed with sense single-stranded G23 oligonucleotide. No competition was observed when double- or single-stranded oligonucleotides containing binding sites for Sp1 or AP2 were included in the reaction as unlabeled competitors (data not shown). Southwestern blotting showed that GST/YB1 fusion protein bound to the double-stranded G23 oligonucleotide with high affinity and bound to antisense single-stranded G23 and the double-stranded SP1 oligonucleotide with low affinity (Fig. 4b). The results of these experiments suggest that YB1 binds to G23 oligonucleotide in a sequence-specific manner. No difference in binding affinity of YB1 protein to G23 and A23 oligonucleotides was detected, however (data not shown). Furthermore, anti-YB1 antibodies failed to affect the binding or mobility of electrophoretically retarded complexes after incubation of G23 oligonucleotide with HepG2 nuclear extract (Fig. 4c).

\section{Cotransfection studies}

To investigate whether YB1 can affect $A G T$ transcription, we cotransfected HepG2 cells with plasmid carrying an AGT promoter-reporter fusion plasmid with $\mathrm{G}$ at position -6 and a pMT2/YB1 vector, placing the entire coding sequence of YB1 under control of the adenovirus major late promoter. Coexpression of YB1 led to decreased $A G T$-driven reporter activity in a dose-dependent manner (Fig. 5).
Fig. 4a-c. a Binding of purified recombinant GST/YB1 fusion protein to G23 oligonucleotides in gel mobility shift assay. ss$G 23(S), \quad s s-G 23(A)$, singlestranded G23 oligonucleotides in sense and antisense orientation respectively; $d s-G 23$, doublestranded G23 oligonucleotide; $d s$-Oct1, nonspecific oligonucleotide encompassing the Oct- 1 binding motif. b Binding of GST/ YB1 protein to G23 oligonucleotides after transfer to nylon membrane (Southwestern blotting). $G S T$, GST protein alone; $G S T / Y B 1$, fusion protein of GST and YB1; $d s-O c t 1, d s-S P 1$, double-stranded oligonucleotides encompassing the Oct-1 and the SP1 motif respectively; other notations are given in a. c Gel mobility shift assay in the presence or absence of anti-YB1 antibody. $N E$, nuclear extract; $r Y B 1$, recombinant $\mathrm{YB} 1$ fusion protein; anti-YB1, anti-YB1 specific antibody a

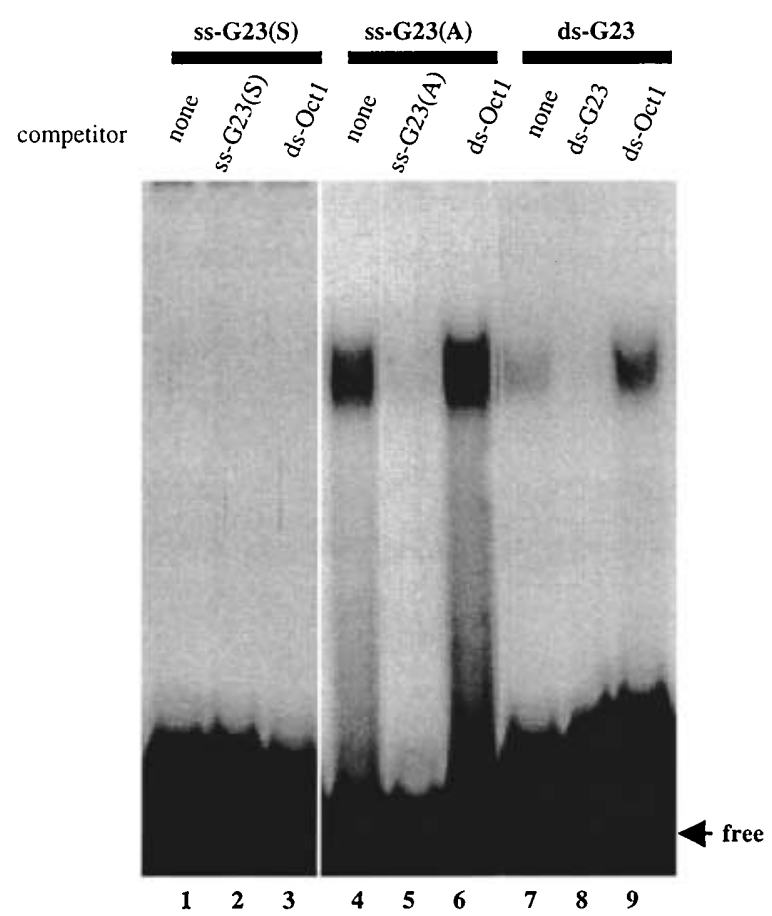

b

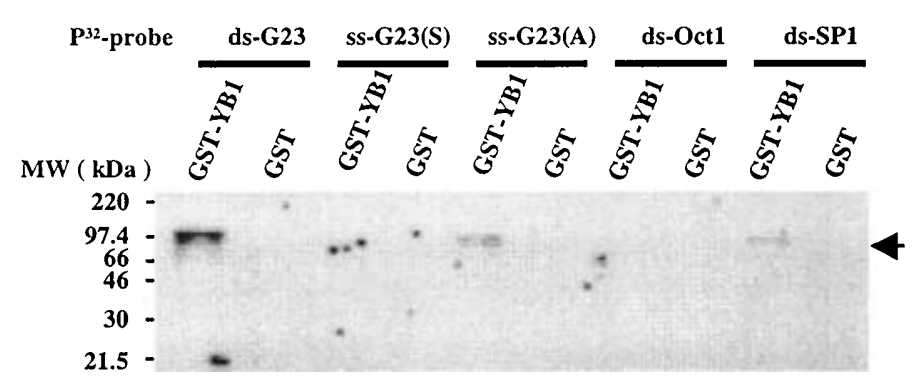




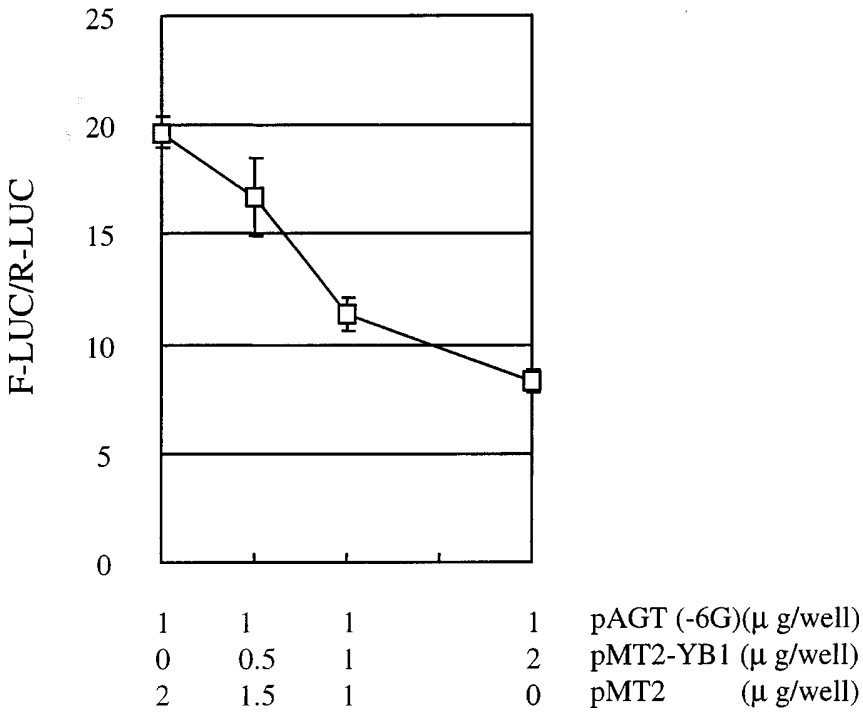

Fig. 5. Effect of YB1 on transactivation of $A G T$ promoter after cotransfection in HepG2 cells. $p A G T(-6 G)$, test vector containing segment $-256,+90$ of the $A G T$ core promoter with $\mathrm{G}$ at the -6 position inserted in front of the Firefly Luciferase reporter; $p M T 2$ $Y B 1$, expression vector placing YB1 coding sequence under control of the adenovirus major late promoter; $p M T 2$, expression plasmid with no coding sequence inserted

\section{Discussion}

The challenge of identifying genetic factors underlying essential hypertension only begins with the inference of genetic linkage and allelic association. Because only partial causation is expected, analysis of functional significance at levels of integration ranging from molecular to organismic will prove necessary and difficult.

The initial hypothesis advanced by Jeunemaitre et al. (1992) was that a moderate but sustained increase in expression of $A G T$ could, over time, account for disease predisposition. Smithies and Kim (1994) and Kim et al. (1995) have developed original transgenic manipulations to provide direct evidence in vivo that a modest increase in $A G T$ gene expression could lead to a chronic increase in arterial pressure. Morgan et al. (1997) have shown that, in placental tissue collected from 39 women heterozygous for the M/ $\mathrm{T}(235)$ polymorphism, $A G T$ mRNA encoding T235 was in significant excess over the M235 counterpart.

Although no functional differences could be detected between recombinant protein with either $\mathrm{T}$ or $\mathrm{M}$ at residue 235 , the $\mathrm{G} / \mathrm{A}(-6)$ polymorphism, in absolute disequilibrium with the M/T(235) polymorphism (Inoue et al. 1997), had to be tested formally for its potential significance. Initial studies have shown that the nucleotide substitution could indeed affect interaction with nuclear proteins and transcriptional activity of the gene in vitro (Inoue et al. 1997). One of the hypotheses generated by this work was that at least two factors may interact with the DNA sequence surrounding the $\mathrm{G} / \mathrm{A}(-6)$ polymorphism: although an activator may bind to both alleles, allele $\mathrm{G}(-6)$ may also show affinity for a competing factor, inducing relative inhibition as a net effect (Inoue et al. 1997). The present work may provide additional support for this hypothesis: (1) when short segments of the $A G T$ core promoter encompassing this polymorphic site are placed in front of a core SV40 promoter, they lead to enhanced expression in a dosedependent fashion irrespective of the variant present at site -6 (Fig. 1a); (2) when segments encompassing site -6 are used as competitors in transactivation assays of the core $A G T$ promoter, the $\mathrm{A}(-6)$ allele has no effect, whereas $\mathrm{G}(-6)$ appears to relieve relative inhibition in a dosedependent manner (Fig. 1b).

The search for a factor binding to the -6 region by screening expression libraries with a specific DNA probe led to cloning of YB1. This protein was originally identified as a CCAAT box binding factor (Ozer et al. 1990; Tafuri and Wolffe 1990) and recent studies have revealed that its nucleic acid binding may not entirely be CCAAT dependent (Gai et al. 1992; Lenz et al. 1990; Sakura et al. 1988; Yan and I 1991). No CCAAT motif can be identified in the vicinity of nucleotide -6 of $A G T$. YB1 has been shown to bind to single-stranded DNA (Bayarsaihan et al. 1996; Hasegawa et al. 1991; Kolluri et al. 1992; MacDonald et al. 1995; Mertens et al. 1997; Ohmori et al. 1996), mRNA (Evdokimova et al. 1995), and damaged DNA, suggesting pleiotropic effects on DNA repair, maintenance/regulation of chromatin architecture, and general mRNA packing (Wolffe 1993). The specificity of the interaction between YB1 and the G23 oligonucleotide was supported by the lack of binding to Oct-1 oligonucleotide, previously validated and used as negative control in gel shift assay experiments (Inoue et al. 1997). This specificity is further supported by Southwestern blotting analysis and gel mobility shift assay with purified recombinant YB1 protein (Fig. 4). Furthermore, the coexpression of YB1 reduces $A G T$ promoter activity in a dose-dependent manner (Fig. 5). Similar experiments involving other genes (Didier et al. 1988; Duh et al. 1995; Goldsmith et al. 1993; Mertens et al. 1997; Ohmori et al. 1996; Ting et al. 1994) have provided evidence that YB1 protein can modulate basal gene transcription through interaction with either double- or single-stranded DNA or with other transcription factors (Li et al. 1997; Raj et al. 1996).

Several experiments, however, did not provide additional support for the hypothesis of a functional interaction between YB1 and $A G T$. No difference could be detected in the relative binding affinity of recombinant $\mathrm{YB} 1$ and the A23 and G23 oligonucleotides (data not shown). YB1 antibodies did not induce supershifting in gel retardation experiments, but not all antibodies do so under such conditions. Finally, the $50 \mathrm{kDa}$ molecular weight of YB1 does not closely match the size of the complex revealed in our UV cross-linking experiments.

To conclude, we cloned YB1 as a factor that may interact with $A G T$ in the region of the G/A(-6) polymorphism. Some observations support the hypothesis that this interaction may be functional, but not all tests performed support this conclusion. The study illustrates the challenge of relating polymorphism to function at the molecular level when differences in degree, rather than gain or loss of function, 
are expected. The existence of other variants in the gene, in various degrees of linkage disequilibrium with the G/A $(-6)$ polymorphism (Nakajima et al., manuscript in preparation) including variants at site -20 (Jeunemaitre et al. 1997) and +67 (Ishigami et al. 1999), and our own unpublished observations suggests that the mechanism by which $A G T$ variation may affect its functional expression may be far more complex than initially anticipated.

Acknowledgments This work was supported in part by Grants HL45325 and HL-55000. We thank Andreas Rohrwasser for his critical reading of the manuscript.

\section{References}

Bayarsaihan D, Enkhmandakh B, Lukens LN (1996) Y-box proteins interact with the S1 nuclease-sensitive site in the chicken alpha 2(I) collagen gene promoter. Biochem J 319:203-207

Didier DK, Schiffenbauer J, Woulfe SL, Zacheis M, Schwartz BD (1988) Characterization of the cDNA encoding a protein binding to the major histocompatibility complex class II Y box. Proc Natl Acad Sci USA 85:7322-7326

Dignam JD, Lebovitz RM, Roeder RG (1983) Accurate transcription initiation by RNA polymerase II in a soluble extract from isolated mammalian nuclei. Nucleic Acids Res 11:1475-1489

Duh JL, Zhu H, Shertzer HG, Nebert DW, Puga A (1995) The Y-box motif mediates redox-dependent transcriptional activation in mouse cells. J Biol Chem 270:30499-30507

Evdokimova VM, Wei CL, Sitikov AS, Simonenko PN, Lazarev OA Vasilenko KS, Ustinov VA, Hershey JW, Ovchinnikov LP (1995) The major protein of messenger ribonucleoprotein particles in somatic cells is a member of the Y-box binding transcription factor family. J Biol Chem 270:3186-3192

Gai XX, Lipson KE, Prystowsky MB (1992) Unusual DNA binding characteristics of an in vitro translation product of the CCAAT binding protein mYB-1. Nucleic Acids Res 20:601-606

Garabedian MJ, LaBaer J, Liu WH, Thomas JR (1993) Analysis of protein-DNA interactions. In: Hames BD, Hggins SJ (eds) Gene Transcription. Oxford University Press, Oxford, pp. 243-293

Goldsmith ME, Madden MJ, Morrow CS, Cowan KH (1993) A Y-box consensus sequence is required for basal expression of the human multidrug resistance (mdr1) gene. J Biol Chem 268:5856-5860

Hasegawa SL, Doetsch PW, Hamilton KK, Martin AM, Okenquist SA, Lenz J, Boss JM (1991) DNA binding properties of YB-1 and dbpA: binding to double-stranded, single-stranded, and abasic site containing DNAs. Nucleic Acids Res 19:4915-4920

Inoue I, Nakajima T, Williams CS, Quackenbush J, Puryear R, Powers M, Cheng T, Ludwig EH, Sharma AM, Hata A, Jeunemaitre X, Lalouel J-M (1997) A nucleotide substitution in the promoter of human angiotensinogen is associated with essential hypertension and affects basal transcription in vitro. J Clin Invest 99:17861797

Ishigami T, Tamura K, Fujita T, Kobayashi I, Hibi K, Kihara M, Toya Y, Ochiai H, Umemura S (1999) Angiotensinogen gene polymorphism near transcription start site and blood pressure: role of a T-to-C transition at intron I. Hypertension 34:430-434

Jeunemaitre X, Soubrier F, Kotelevtsev YV, Lifton RP, Williams CS, Charru A, Hunt SC, Hopkins PN, Williams RR, Lalouel J-M, Corvol P (1992) Molecular basis of human Hypertension: role of angiotensinogen. Cell 71:169-180

Jeunemaitre X, Inoue I, Williams C, Charru A, Tichet J, Powers M, Sharma AM, Gimenez-Roqueplo AP, Hata A, Corvol P, Lalouel JM (1997) Haplotypes of angiotensinogen in essential hypertension. Am J Hum Genet 60:1448-1460
Kato N, Sugiyama T, Morita H, Kurihara H, Yamori Y, Yazaki Y (1999) Angiotensinogen gene and essential hypertension in the Japanese: extensive association study and meta-analysis on six reported studies. J Hypertens 17:757-763

Kim HS, Krege JH, Kluckman KD, Hagaman JR, Hodgin JB, Best CF, Jennette JC, Coffman TM, Maeda N, Smithies O (1995) Genetic control of blood pressure and the angiotensinogen locus. Proc Natl Acad Sci USA 92:2735-2739

Kolluri R, Torrey TA, Kinniburgh AJ (1992) A CT promoter element binding protein: definition of a double-strand and a novel singlestrand DNA binding motif. Nucleic Acids Res 20:111-116

Kunz R, Kreutz R, Beige J, Distler A, Sharma AM (1997) Association between the angiotensinogen 235T-variant and essential hypertension in whites: a systematic review and methodological appraisal. Hypertension 30:1331-1337

Lenz J, Okenquist SA, LoSardo JE, Hamilton KK, Doetsch PW (1990) Identification of a mammalian nuclear factor and human cDNAencoded proteins that recognize DNA containing apurinic sites. Proc Natl Acad Sci USA 87:3396-3400

Li WW, Hsiung Y, Wong V, Galvin K, Zhou Y, Shi Y, Lee AS (1997) Suppression of grp78 core promoter element-mediated stress induction by the dbpA and dbpB (YB-1) cold shock domain proteins. Mol Cell Biol 17:61-68

MacDonald GH, Itoh-Lindstrom Y, Ting JP (1995) The transcriptional regulatory protein, YB-1, promotes single-stranded regions in the DRA promoter. J Biol Chem 270:3527-3533

Mertens PR, Harendza S, Pollock AS, Lovett DH (1997) Glomerular mesangial cell-specific transactivation of matrix metalloproteinase 2 transcription is mediated by YB-1. J Biol Chem 272:22905-22912

Morgan T, Craven C, Nelson L, Lalouel JM, Ward K (1997) Angiotensinogen T235 expression is elevated in decidual spiral arteries. J Clin Invest 100:1406-1415

Ohmori M, Shimura H, Shimura Y, Kohn LD (1996) A Y-box protein is a suppressor factor that decreases thyrotropin receptor gene expression. Mol Endocrinol 10:76-89

Ozer J, Faber M, Chalkley R, Sealy L (1990) Isolation and characterization of a cDNA clone for the CCAAT transcription factor EFIA reveals a novel structural motif. J Biol Chem 265:22143-22152

Raj GV, Safak M, MacDonald GH, Khalili K (1996) Transcriptional regulation of human polyomavirus JC: evidence for a functional interaction between RelA (p65) and the Y-box-binding protein, YB-1. J Virol 70:5944-5953

Sakura H, Maekawa T, Imamoto F, Yasuda K, Ishii S (1988) Two human genes isolated by a novel method encode DNA-binding proteins containing a common region of homology. Gene 73:499-507

Singh H, LeBowitz JH, Baldwin AS Jr, Sharp PA (1988) Molecular cloning of an enhancer binding protein: isolation by screening of an expression library with a recognition site DNA. Cell 52:415-23

Smith DB, Johnson KS (1988) Single-step purification of polypeptides expressed in Escherichia coli as fusions with glutathione Stransferase. Gene 67:31-40

Smithies O, Kim HS (1994) Targeted gene duplication and disruption for analyzing quantitative genetic traits in mice. Proc Natl Acad Sci USA 91:3612-3615

Tafuri SR, Wolffe AP (1990) Xenopus Y-box transcription factors: molecular cloning, functional analysis and developmental regulation. Proc Natl Acad Sci USA 87:9028-9032

Ting JP, Painter A, Zeleznik-Le NJ, MacDonald G, Moore TM, Brown A, Schwartz BD (1994) YB-1 DNA-binding protein represses interferon gamma activation of class II major histocompatibility complex genes. J Exp Med 179:1605-1611

Vinson CR, LaMarco KL, Johnson PF, Landschulz WH, McKnight SL (1988) In situ detection of sequence-specific DNA binding activity specified by a recombinant bacteriophage. Genes Dev 2:801-806

Wolffe AP (1993) Structural and functional properties of the evolutionarily ancient Y-box family of nucleic acid binding proyeins. BioEssays 16:245-251

Yan C, Tamm I (1991) Molecular cloning and characterization of interferon alpha/beta response element binding factors of the murine $\left(2^{\prime}-5^{\prime}\right)$ oligoadenylate synthetase ME-12 gene. Proc Natl Acad Sci USA 88:144-148 